\title{
NARRAR (EN) LA "POST": \\ LA ESCRITURA DE ÁLVARO BISAMA, ALEJANDRA COSTAMAGNA, ALEJANDRO ZAMBRA ${ }^{1}$
}

\author{
Alejandra Bottinelli $W$. \\ Universidad de Chile \\ alejandra.bottinelli@gmail.com
}

RESUMEN / ABSTRACT

La Post es el nombre que este ensayo da a un tiempo: el que sucede a la reposición de la autoridad política legítima en Chile en los años 90, y a un deseo: el del retorno de una potencia de organización del sentido que había existido antes de la catástrofe de la cultura que fue la dictadura, y a su expectativa en el largo período que siguió a la bella pero breve epifanía del triunfo popular que la derribó (el 'NO'). Las escrituras que aquí se hermanan expresan las tensiones de un proceso histórico cuya carencia de nombre propio (la "transición") evidencia la vocación elusiva de una realidad que pospone (no concluye aún de posponer) el encuentro de los sujetos en horizontes comunes. Voces, las de estos escritores, que se exponen desde esa falta constitutiva y que intentan la recomposición de un sentido posible, de un crucigrama formado por otras voces, también perdidas, en medio del ruido intenso que aún no permite oírlas, en la Post.

Palabras clave: Álvaro Bisama, Alejandra Costamagna, Alejandro Zambra, literatura chilena contemporánea, transición política, la Post.

The Post is the name that this essay gives a time: what comes after to the recovery of legitimate political authority in Chile in the '90s; a desire: the return of a potency of organization of meaning that had existed before the catastrophe of culture that was the dictatorship, and his expectation in the long period that followed the beautiful but brief epiphany that was the

1 Este trabajo fue motivado por las reflexiones del Coloquio "Después del desastre: cuatro décadas de narrativa chilena. 1973-2013", realizado en la Universidad de Chile en octubre de 2013 , y fue elaborado en el marco del proyecto de investigación "Modernización y cultura en América Latina: pensamiento y literatura" (Fondecyt, $\mathrm{N}^{\circ} 1130031$ ), del cual la autora es co-investigadora. 
popular triumph, that downed it (the 'NO'). The writings here twinned expressed tensions of a historical process whose lack of proper name (the "transition"), evidence of the elusive vocation of a reality that postpones (not yet concluded to postpone) the identification of subjects in common horizons. Voices, of these writers, set out from that constitutive lack and try to recompose a possible sense, a puzzle formed by other voices, also lost, amid the loud noise which still does not allow hear them, in the Post.

KEYWords: Álvaro Bisama, Alejandra Costamagna, Alejandro Zambra, Contemporary Chilean literature, political transition, the Post.

"Entonces salimos nosotros del tiempo y se acabaron los mitos y las memorias, la hora de la verdad nunca llegó y muchos de nosotros nos convertimos en focas, en gusanos, anacondas de paso. Sobre nuestro cadáver se modernizó la muerte" Gustavo Ogarrio. La mirada de los estropeados

"Y no sabe mentir / la boca del muerto" Leopoldo María Panero. Teoría del miedo

Todo avanzaba al revés, no es que retrocediera (no se rebobinaba) sino que avanzaba, pero hacia atrás. Las historias se descomponían en vez de componerse, los triunfos, pasajeros o no, se deshilvanaban hilo por hilo hasta quedar nuevamente enredados en la madeja informe de la que habían salido. No había futuro porque nuestro presente estaba atascado en el pasado, una gran polea invisible de historias que no terminaban de morir nos tiraba hacia ese pasado, que era un origen.

Un pasado vencido, no derrotado, o no solo eso, sino descompuesto, como los yogures que se exceden en la fecha límite, amenazando con enfermarnos del estómago. Un territorio de la podredumbre ése, nuestro pasado, era, sin embargo, todo lo que teníamos.

Por eso, avanzar hacia atrás era andar a contrapelo, abriendo la realidad y provocando, al paso, la emergencia de las heridas, convertidas en nudos desde donde nacían las ramas de la genealogía de un mal, uno que se había metido en nuestras casas, en nuestras camas de hospital, que había intervenido nuestros partos. Un mal que era lo que debíamos conjurar primero que todo, primero que todo. Y que solo podríamos exorcizar echando luz sobre esas cicatrices que formaban, suponíamos, el único dibujo desde el cual nos 
sentíamos capaces de retomar el sentido: un boceto sobre nuestras experiencias fallidas, sobre nuestras derrotas, nuestras.

Andar a contrapelo fue entonces el cumplimiento de un destino (la meta es el origen, decía Karl Kraus ${ }^{2}$ ), una necesidad vital al precio de un dolor o de un desamparo (que es un estado del dolor): el abandono de la carretera y la opción por los caminos entierrados. Entre cerro y cerro, entre pueblo y pueblo, por detrás de las alambradas habríamos de andar siguiendo las huellas que marcaron las personas que huyen, los animales heridos en los carretones, el olor de agonizantes pescados de criadero en camiones llenos, otros días, con la basura de las ciudades. Allí estábamos: entre los cercos, tras los caminos, y en las noches, también agazapados. Aprendimos a encogernos, en las noches.

Por esos y otros lugares de atrás, por esas esquinas y esas cornisas es por donde creo que ha andado la narrativa de la Post (dictadura) en Chile ${ }^{3}$, o con más precisión, la de nuestros mejores narradores de la Post, entre ellos, Alejandra Costamagna (1970), Álvaro Bisama (1975) y Alejandro Zambra (1975), cuyas escrituras aquí nos ocupan, y que, si le concedemos al menos unos centímetros a Oscar Wilde en eso de que es la vida la que imita al arte (no hay, en Japón, decía él, las japonerías que provee la literatura o la pintura, solo existen después de imaginadas ${ }^{4}$ ), vamos a permitirles que nos delineen, y vamos incluso a tratar de preguntarles qué es lo que su literatura le dice a la vida de esas vidas que vivimos una buena parte de chilenos en la Post.

Dos declaraciones finales en el inicio, para ahorrar tiempo: declaro que intuyo que la escritura de Alejandra Costamagna, de Álvaro Bisama y la de Alejandro Zambra, la de cada uno de ellos y la de los tres juntos, que lo que ellos han hecho en la palabra ha conseguido no solo alargar los plazos de caducidad de nuestra literatura nacional, mil veces condenada a muerte (aunque mil más en la Post) sino ayudarnos, a otros tantos congéneres de ese

2 En la pieza "El hombre agonizante" ("Der sterbende Mensch", 1913), dice Dios al Hombre: "Yendo en lo oscuro, supiste de luz más clara. / Ahora estás aquí y me miras cara a cara. / Buscabas mi jardín y mirabas hacia atrás. / Seguiste en el origen. Origen es destino. / Tú, que jugaste al vivir sin perder tu camino, / no tienes ya hombre mío por qué esperar más" (Kraus 159-160).

En adelante en el trabajo la "Post", el único período histórico que merece, a mi entender, en Chile esta denominación, con la única excepción de la guerra del Pacífico, que representó el quiebre de nuestro lugar en América así como la dictadura cívico-militar pinochetista lo hizo con nuestro lugar en la modernidad y la democracia.

Intenciones. La decadencia de la mentira 48. 
segmento etario mil veces también condenado, a andar un camino posible hacia aquel origen velado, oscuro y terrible, un camino que gracias a y por sus letras, hacemos hoy menos desamparados (o desolados, en la forma de Gabriela).

Y declaro, además, que cuando haga de este texto una exposición (siempre patética) de una personal pertenencia a la generación de la que ellos forman parte y que compartimos todos los nacidos cerca del Golpe, el lector tiene derecho a desarrollar anchamente el rictus de desacomodo que ya viene formando en los labios, y no porque reniegue de mi nacimiento en aquella hora naranja de un marzo de 1974, sino sobre todo porque me atrevo a afirmar que la gran mayoría de los hijos del Golpe o hijos de la dictadura o hijos de ya sabemos quién y de quién sabe dónde aprendimos a caminar justamente para romper esa filiación negra; $y$, por lo tanto, firmo bajo mi lata declaración que la primera persona plural de arriba y de más abajo se debe a simple simpatía literaria -todos mentimos un poco al incluirnos o desincluirnos en un colectivo, mentimos porque construimos un comentario, una escritura que nos encuentra siempre un poco desajustados de las interpretaciones totalizantes, por suerte que los hijos mentimos. Menos mal que mentimos-.

\section{LA POST}

Hubo una fiesta en Chile, de la democracia, y todos la vivimos, pero duró poquito. Al tercer día ya nadie estaba en capacidad de resucitar y las calles se llenaron de escobillones humanos barriendo guirnaldas bajo un sol ceniciento que nos molestaba a la vista. Nos pusimos lentes oscuros mientras la TV pasó novelas con la gente vestida de color flúor. Algunos se parapetaron en sus nuevos gabinetes a pasar la resaca. Pero ya estaban todos más o menos hechos tira. Nuestras primeras certezas salieron de ahí: que la alegría era cortita y las guirnaldas al día siguiente parecían guaipes pisoteados; que todos se habían entrado y que en adelante nos tendríamos a nosotros nada más. Al barrer el sol ${ }^{5}$ íbamos a tener que salir a buscar por los caminos nosotros

$5 \quad$ "He barrido el sol", es uno de los temas del disco con que debutó el grupo musical chileno Los Tres (Alerce, 1991). Parte de su letra dice: "He barrido el sol/ de este lugar/ Arrastré el calor/ del basural/ que brillaba sobre ti/ no sé si fue tan así. // Con mi voz de plata/ haré temblar/ romper los cristales/ llorar, esperar/ y en tu cama brillará/ el sol que no volverá". La 
solos, cabritos -bien que ya son mujercitas y hombrecitos-, nuestros padres ya habían hecho mucho con pasar el período oscuro salvos (no digo sanos, quedemos en que salvos). Aunque no sabíamos por dónde: la piel de las calles estaba medio descuadrada o era nuestra vista, pero por todas partes las cosas se perdían como si se las hubiera tragado el arcoíris ése que venía en las tarjetas.

Por esos días, en una habitación en el centro del mundo, Kurt Kobain se seguía hiriendo y yacía con las sienes atravesadas. En Santiago de Chile, en el piso helado de una pequeña micro en dirección al barrio alto de la ciudad, 162 balas policiales acribillaban a tres jóvenes extremistas que habían robado un banco ${ }^{6}$.

Hubo una generación que aprendió a andar su veintena con la noticia de la soledad y de la muerte mientras la tele pasaba Adrenalina ${ }^{7}$ y la iglesia se condolía por la crisis de la moral sexual. Miedo y soledad, paranoia y esquizofrenia, he allí el mundo que se le ofrecía a La Post chilena. Su riff digamos, generacional, tiene que ver con esa muerte y con esa soledad como repetición cotidiana de aquélla.

Si alguna certeza teníamos era la del desastre, es decir, de que un momento cualquiera era siempre pasible de convertirse en su propio declive; que nuestra

composición me parece sugerente como metáfora del estado de ánimo que, propongo aquí, marcó y marca aún a la "Post", y sobre/contra o junto al cual emerge la voz de estas escrituras.

Así usaba nombrar la retórica dictatorial a los jóvenes de izquierda participantes en acciones directas de propaganda u otras, contra el dictador. Ese adjetivo se proyectó en la retórica de los gobiernos de la transición para los participantes de organizaciones antisistémicas. Nos referimos aquí al llamado "Caso Apoquindo", ocurrido el 21 de octubre de 1993, donde fueron asesinados Raúl González Órdenes, de 23 años, Yuri Uribe Toro y Alejandro Sosa Durán, ambos de 24 años, militantes del Movimiento Juvenil Lautaro, en la calle Apoquindo en la comuna de Las Condes, cuando la micro en la que escapaban de un asalto a un banco fue acribillada por Carabineros y sobre la cual, según los peritajes, los policías descargaron más de 300 balas, a pesar de las señales de rendición de los lautaristas y de la presencia de una veintena de pasajeros, tres de los cuales también fueron heridos de muerte por los policías: Marcos Villegas, Tatiana Navarro Valdés (19 años) y Sergio Valdés Valdés (27 años). Álvaro González, de 22 años y Oriana Alcayaga, hija de un ejecutado por la caravana de la muerte, fueron sometidos a torturas y luego de largos procesos judiciales ( 8 años), fueron condenados por la Justicia Militar a presidio perpetuo por la muerte del guardia de seguridad del banco. Una novela reciente de Gonzalo Ortiz Peña lleva como título Niños extremistas (2013).

Adrenalina fue una telenovela chilena emitida durante el segundo semestre de 1996 por la señal de Canal 13, perteneciente a la Pontificia Universidad Católica de Chile. Escrita por Pablo Illanes y dirigida por Ricardo Vicuña. 
vida transitaba por la delgada línea de la cual mañana nos veríamos caer. Sobre el filo de una navaja estaba nuestra suerte -como habla el griego ${ }^{8}-$, un pogromo contra la juventud y las ideas había sido cometido y cualquier día podemos amanecer un 12 de septiembre y las calles vacías o un 13 de septiembre y todo nuestro mundo de hace unsiglo-dosdías hecho trizas ${ }^{9}$. Y entonces fuimos jóvenes apurados pero con una melancólica y envejecida certidumbre en los bolsillos: todo llegaba truncado para nosotros y aún eso trunco más temprano que tarde, se acabaría. Una rara experiencia de la caducidad, la nuestra. Como el niño de La edad del perro (2014), la novela de Leonardo Sanhueza (1974), una de las certezas que cultivó esta generación en su infancia era que el mundo se finiquitaría y pronto. Algo parecido al apocalipsis nos mandaría al fin de todo el año 2000. O antes. Nos estrellaríamos con el sol o miles de soles y meteoritos nos caerían encima. Y eso era parte de la conversación diaria. Era eso por supuesto también una reminiscencia de la época de cuando si recogías el lápiz en la calle, ipum! Se acabó, de un segundo al otro (los terroristas ponen bombas hasta en los lápices, me dijo una vez una compañera hija de un locutor de tv de la dictadura, teníamos ocho años y desde ese día caminé mirando de reojo las veredas a ver si le pillaba los cables a los envoltorios, a las cajas, a los lápices tirados). Caminábamos hacia atrás, con la polea tironeándonos, avanzábamos descontando, para volver a ese origen que, lo sospechábamos, podía ser también el fin, es lo que trato de decir.

Entonces, como en la casa colonizada por larvas de Romina Reyes, acá también era "la hora azul, ese momento en que no se sabe si amanece u oscurece" (Reinos 78) y en el cual ni siquiera nos pudimos formular la pregunta sobre qué quedaba del antiguo lenguaje, del habla callejera y cotidiana de hace tanto tiempo -dos días, meses, un par de años-, pues simplemente ya no existía, o no encontrábamos sus huellas. Para nosotros, "hablando en serio -como Alejandro Rossi-, Chile, entre 1970 y 1973, no existió" (Manual del distraído 104), la UP, la "única gran experiencia ético-política de la historia

Heródoto. Historia 564-565.

Fue Soledad Bianchi quien iluminó para mí esta feroz discontinuidad espaciotemporal que imprimió el Golpe a la vida cotidiana chilena de la época. Ella comentó cómo al observar desde la calle su lugar de estudios, el Pedagógico, el día 13 de septiembre todo absolutamente todo era distinto. Soledad habló de esto en una mesa en un seminario que organizó el Departamento de Literatura de la Universidad de Chile en conmemoración de los 40 años del Golpe. 
nacional" -en palabra de Patricio Marchant (Escritura y temblor 213)-, esa no la olimos ni la pudimos imaginar más que monstruo deforme como nos la contó el dictador, o hecha de luz vieja, un papel de diario que queda en el suelo, como cuenta la voz de Estrellas muertas (48 y 69).

En esa hora azul, en ese trance de morir el día y nacer otro -o al revés, no se sabe-, es que ubico las escrituras de nuestros autores. Sin materiales firmes a qué asirse, levantando un lenguaje como se reconstruye un edificio bombardeado o como se pinta uno implosionado por su propia decadencia, nuestros escritores, estos escritores de la Post chilena hicieron del lenguaje una retaguardia -en palabra sartreana- que se opone a lo vencido, conviviente perturbadora de ese mutismo que era el sonido del día, como en El zapato chino (1979), el filme de Cristian Sánchez: el crujido de la soledad y de la mudez (¿hay un sonido de la mudez? Hay, afirmo, lo hubo en Chile, era cosa de andar por las calles entre Av. Matta, Blanco, Club Hípico en el año 1978, como muestra ese zapato chino que apretaba la sangre ${ }^{10}$.

¿De qué están compuestas, entonces, estas escrituras? De restos, ruinas, faltas, fallos, equívocos y callejones sin salida, defaults más precisamente

10 Para asegurar la consumación de su poder a través de la representación, la dictadura, como "fingimiento de una autoridad ausente" (Iancilevich 140), se había dedicado programáticamente a la destrucción de la sintaxis existente: a través de la supresión de la disonancia - del "libertinaje de las modulaciones y los cambios de tono" (Lihn 100)-, de la estigmatización y el borramiento de vocablos y modos del habla cotidiana, así como de la obligación del uso de imposturas comunicativas que expusieran su dominación total sobre los individuos, sus cuerpos y su lenguaje. Verbigracia la reposición de la autoridad legítima esperábamos, con la Post, recobrar también esa sintaxis. El fin de la dictadura, suponíamos, nos devolvería una forma de organización del sentido que había existido antes del Golpe, según nos contaban. Pero no pasó. Porque los textos, los tejidos de la cultura chilena del siglo $\mathrm{XX}$, los relatos de trascendencia colectiva, las formas para nombrar al/a otro/a en un horizonte común se habían arcaizado, habían sido exitosamente enterrados por la discontinuidad que la dictadura introdujo en el relato de la historia de Chile, que condenó como anti-moderno todo el período que le antecedió (la modernización autoritaria se asumió como única modernidad posible para el país del orden, de la excepción, el milagro chileno, ejecutado por los ingleses, por los jaguares de Latinoamérica). Esos tejidos de formas y sentidos se quedaron, entonces, asilados en un tiempo-experiencia perdido y no recobrado (una pérdida que, pienso, se debió a la particularidad de nuestra Post, que aceptó habitar un suelo neoconservador que no estuvo en debate, justamente porque ese silencio fue condición de la transición y de su forma de comunicación: la política de los consensos. El 'NO' (y toda su carga crítico-negativa) había sido una maravillosa epifanía, breve.

Sobre la modernización autoritaria, es iluminador el trabajo de Javier Pinedo C., "Chile a fines del siglo XX: entre la modernidad, la modernización y la identidad”. 
defaults, con toda su ambigüedad: incomparecencias y renuncias, pero también rebeldías. Y necesidades. El de ellos podemos nombrarlo sobre todo un estilo de la necesidad -como dice Alejandro Rossi, y como dice Alejandro Zambra citando a Alejandro Rossi ${ }^{11}$.

Son voces, las suyas ("voces, son voces", insiste Álvaro Bisama a una comentadora de Los muertos $^{12}$ ), cuya magia se juega tanto en dejar decir, en abrir la compuerta pródiga de historias, como hace el mismo Bisama (de Música marciana a Los muertos) y hace Alejandra Costamagna (de Últimos fuegos a Animales domésticos), como en sentar el pie, exponiendo la distancia entre el disfraz, la piel y el tatuaje ${ }^{13}$ de narradores que se visten de autores no tan implícitos y de personajes que se doblan en sí o se maquillan de ausentes, que se miran en espejos deformes y luego restablecen, fijan sus contornos para nuevamente desarmarlos, difuminarlos a través de otros, como hace Costamagna en historias que son casi ucronías unas de otras (la madre-siempre la madre-, el padre -siempre el padre-, la tía; el Solitario, la Inolvidable, Canossa, la perra) y como hace Alejandro Zambra con esos personajes suyos que son como adaptaciones, tránsitos -equívocos los más, búsquedas al fin-, no puntos, sino trayectorias (Julián, que es como una segunda oportunidad de Julio y del escritor, casi siempre del escritor, del personaje del escritor).

Voces que antes que todo se exponen desde la falla, desde esa falta constitutiva que es la vivencia de la catástrofe: "Me quedé donde mismo...No esperaba nada porque yo mismo no era nada", afirma el narrador de Estrellas Muertas (Bisama 83); "Soy la hija de puta. Ellos me mataron. Me fulminaron mis padres... Soy la hija del reptil. Los reptiles nos recogemos en el silencio helado de la tierra"; la protagonista de Cansado ya del sol (Costamagna 211); "Soy un corresponsal, pero me gustaría saber de qué", el escritor que habla en Yo fumaba muy bien (Zambra, Mis documentos 137).

\section{LAS DERROTAS DE BISAMA}

Perec dice (El viaje de invierno) que el libro que conmociona a Degraël está compuesto en su parte primera de una historia de características iniciáticas

$11 \quad$ No leer, 64.

12 Cf. Rovaretti.

13 En la fórmula de Guadalupe Santa Cruz (28). 
marcada por hitos de sucesivos fracasos del protagonista. Me gusta que sea así, que los pasos, que las puertas dejen de conducir a la victoria y se conviertan en mojones hacia el declive, a ningún lado, es decir, no-mojones: hitos hacia ningún lugar, no-hitos que conducen de vuelta a la aspiración inicial pero esta vez vencida, igual que esas marcas que en el camino del vidente en Ruido de Álvaro Bisama conducían a la falsa aparición y de ahí como en un tobogán de alcohol, pinturas corridas y esperanzas contrahechas al fondo del pozo, a los ojos semiabiertos del falso profeta que solo aspiraba a mirarse mirando.

Uno podría pensar en el fracaso del vidente como el fracaso de la realidad ante la escritura que es, en los hechos, una mentira deliberada, un desvío del camino. Un ardid. Eso es tal vez lo más duro de esa historia de Bisama: que la vida termina por correr el velo de la ficción a cambio de una realidad que no solo le es parásita, sino que le queda chica, que no alcanza. ¿Cómo se levanta la vida cuando se ha develado una farsa?, ¿cómo se levanta la vida cuando atrás del escenario hay solo vacío - un pueblo, cualquier Alhué de Chile, vacío?

Creo que en esa exposición del fracaso que elaboran, una tras otra, las escrituras de Bisama hay la proposición de una vía, también, para abrir las posibilidades del vivir (la literatura no repara traumas, de acuerdo, pero sí puede sentarse al lado y marcar el sonido de la declinación, el ritmo que distingue el caer de sus cabellos, y antes, las ansias de una vida; no da de comer, solo las palabras que nombran esa necesidad). Un particular y antiguo sentido de la polis funda esta enunciación que se da a contarse en generosidad de historias y de palabras, tremendas, extremas, profusas, estas sí que rizomáticas; hay aquí algo de esa antigua tradición de un mundo que no podía imaginarse a sí mismo sin exponerse teatralmente: no concebía felicidad sin espectáculos y fiestas, ni dolor sin libaciones y largas sesiones de llanto, todo bajo la presencia de unos dioses siempre curiosos por cada episodio del cruel destino de los hombres ${ }^{14}$. Hay en la escritura de Bisama una dramatización de la vida que no elude el modo de la tragedia y que recuerda a las formas del distanciamiento brechtiano, con historias que escarban, que refieren a un territorio que se escucha como nuestro ruido inconsciente, de nuestras vidas negadas, que se ajusta más a los reversos que a las evidencias, a ese tiempo alojado en el cuarto de atrás pujando por manifestarse. De

14 Es Friedrich Nietzsche quien habla de esa vocación de hacer público el acontecer, en las culturas de la Antigüedad (100-101). 
Bisama puede decirse lo que de un gran escritor dice George Steiner: pesca en su red "la confusión viva de la vida inconsciente"15.

Agregaría que esta dramatización permite otorgar el primer plano a esas voces "que están tras la nuestra" (Fotos 41) no solo como inconsciente, sino como oportunidades derrotadas, aquellas que no tuvieron futuro, voces vencidas, que no llegaron a manifestarse: estrellas muertas que ya no alumbraron más. Destinos como las llamadas de los no predestinados, de los no señalados en el cuento de Julio Ramón Ribeyro: de los "medios", los que no tienen un "entonces", los que estaban desposeídos de la palabra entonces ${ }^{16}$.

Con el pulgar apretado dentro del puño como símbolo de aferrarse a la vida pasan los personajes de Bisama, de Crónicas marcianas a Los muertos, cada cual pareciera repetir el gesto. Aquí nadie se entrega, ni siquiera cuando cuentas los minutos en reversa para tu muerte como la mujer de ese cuento, Ciento setenta y dos mil ochocientos segundos ${ }^{17}$. De todos ellos podríamos decir con Rossi: "allí está la mezcla fascinante: parodia y minucia. Y esa especie de detención en que aparece-intensa- la imagen" (100). Porque lo que hay en su escritura es la exposición de la ruina, de esa que habla Benjamin, pero sobre todo de esa que Leopoldo María Panero dice, asalta al lector en callejuela oscura, en el cruce entre caminos ${ }^{18}$.

Se escribe, entonces, para oponer al texto como mandamiento, como sentencia, sus restos, las estrellas muertas que quisieron florecer en nuevas vidas en la escritura. Voces que no pretenden trascendencia, sino solo hablar. Es más importante escuchar que enunciar: una caja de resonancia: ceder el espacio, dar la voz. En una entrevista a propósito de la publicación de su Música marciana, dice Bisama: "Eso es lo que quería: una novela hecha de tantas historias que llegaran a saturarlo todo. Así me gusta: el ruido de las historias que chocan unas contra otras y saturan las páginas"19. Contra la disminución del lenguaje que, ya tenemos noticia, es condición de La Post, Bisama opone su vitalismo, sobrecarga si es necesario. Necesario.

15 Para George Steiner es lo que hace el Ulises de James Joyce (50).

16 Ribeyro, "La encrucijada". La palabra del mudo.

17 De Los muertos.

18 Dice Leopoldo Panero: "Viva el perder, viva el brillo oscuro de la ruina / que asaltas al lector en callejuela oscura / donde Hécate brilla en el cruce entre caminos / ah Circe la traidora, que saqueas Sicilia / y le arrancas su nombre bautizándola / con el nombre del pájaro y la ruina" (98).

19 En Zúñiga, "Entrevista” 13. 
Uno lee Los muertos como si se tratase de un comentario de un estado del espíritu, del ánima postdictatorial, donde los muertos, los que han estado muertos de la palabra, cobran vida. Son vicisitudes, anécdotas, de una densidad de tiempo, espesura y proyección sobre todo en el ambiente: marcas en el cuerpo de la época.

La trayectoria completa de estos muertos de Bisama se parece a la del protagonista de ese otro cuento de Ribeyro ${ }^{20}$ : el hombre sigue una mancha de sangre hasta que se da cuenta de que era la suya propia, estaba muriendo en su lecho y repetía el camino hacia ese lugar en un oscuro cuarto, asistía al espectáculo de su propia muerte. Hay algo de eso en estas historias, narradores que ven o recuerdan el trayecto de la declinación de los personajes que caen a su lado, pero que al caer, caen con ellos, que terminan, como en Estrellas muertas, en un hotel de traficantes y puteros en la calle Pedro Montt. Recuerda también al pasillo de Camanchaca, la novela de Diego Zúñiga: un joven atrapado en su historia de infancia, en su tragedia de familia que es su marca de nacimiento.

Son estos de Bisama unos hablantes que vuelven los ojos expectantes, como cuando en el poema de Vallejo los llaman desde el hombro, solo que aquí, al volverse, no había nadie: estaban solos ${ }^{21}$. Ellos saben bien que "la actualidad es a menudo anacrónica" 22 , la sufren, pues viven en un mundo en el que mucho es de ayer, de un ayer antiguo, en esa experiencia extrema de la caducidad del fin del siglo XX, donde desde la caída del muro hasta el desarrollo de las $\mathrm{TIC}^{23}$, buena parte del paisaje humano anterior se ha anacronizado. Ellos escriben, entonces, sabiendo que cada texto es siempre un poco un texto de ese ayer antiguo, pero lo hacen sin ceder a la nostalgia, no hay acá nada de "las formas catárticas y confesionales del testimonialismo" (Avelar 181), sino la voluntad de reponer estas voces actuales en un tono que no las reduzca al pasado. Volverlas a la vida.

Uno podría pensar en los cuentos de Los muertos como traspasados por el ruido ese que llaman del apocalipsis, el hum acechante que nos avisa que ya

20 "La huella". La palabra del mudo.

$21 \quad$ El poema de César Vallejo: "Hay golpes en la vida tan fuertes... yo no sé! / Y el hombre... Pobre... pobre! Vuelve los ojos, como / cuando por sobre el hombro nos llama una palmada; vuelve los ojos locos, y todo lo vivido / se empoza, como charco de culpa, en la mirada" (1.1-4). Vallejo, "Los heraldos negros" 13.

22 Borges ctd. por Julio Ramón Ribeyro, "Introducción”. La palabra del mudo 10.

23 Tecnologías de la información y las comunicaciones. 
estamos en camino a nada. El ruido está allí y no cede, en una narración nada de limpia, como su eco que es Música marciana, traspasada por el exceso. En Los muertos, parecido a la cámara de un cine como el del surcoreano Kim Ki-duk, hay una presencia acechante que pareciera perseguirnos durante todo el relato. Y que se parece al ruido de nuestro inconsciente, la música de esa caja negra donde habitan nuestros muertos, los muertos ciertos que son los muertos de la palabra. Ellos hablan, hablan los que viven en nuestros deseos y nuestras pesadillas, que cumplen hasta lo inimaginable, que fracasan estruendosamente sobre un cementerio modernizado como el que aloja a los de Ogarrio. Esa presencia de todo aquello negado es la que da unidad a un texto extraordinario que acumula una memoria por retazos pero logra "que los fragmentos parezcan tener un solo tono, ser una sola voz" (Fotos 39).

\section{LAS HISTORIAS SE QUEMAN: ALEJANDRA COSTAMAGNA}

El instante inmediatamente anterior a que la hoja metálica abra la piel de la artista para trazar el recorrido del daño, adueñarse de él inscribiendo en el tiempo la palabra que identifica, que agravia: "perra", ese instante de silencio, esa duda, ese interregno que acelera el pulso y permite oír el aliento de la artista guatemalteca Regina José Galindo antes de inscribir cada letra del agravio en su cuerpo, eso es lo que importa a la escritura de algunas afrentas, pienso yo. El momento en que el/la artista pronuncia su voluntad de apropiación, ese espacio de tiempo en que el ser humano toma aliento y que condensa toda su existencia, su miedo y su finitud de tal ser humano, es, propongo, el que importa también en las escrituras de Alejandra Costamagna: el posible que se abre no por la identificación con algún excluido (no hay identificación aquí: su escritura no es un cuerpo, sino una transformación -no busque aquí al héroe, no pierda el tiempo que no lo hay-), sino por la apropiación de la afrenta, su reinscripción radical: repetida.

Ante la guerra, esa "grosería ejercida sobre el tiempo", esa banalización del acontecimiento como si fuera "mercancía mediocre" -como dice el angoleño, Gonçalo Tavares ${ }^{24}$ - de la que el ser humano es su residuo o su tiempo extra, su excedente prescindible, el inútil cuerpo humano (el "minúsculo y quebradizo 
cuerpo humano", en palabra de Walter Benjamin ${ }^{25}$ ) halla su posibilidad de reconstituirse sobre todo en la potencia inexpugnable de su desidentificación, en su capacidad de ser un cuerpo que muta, que se extiende en el tiempo, en el transcurso y se extraña de sí mismo, es decir, que se señala máscara, que es capaz de reinscribirse sobre sí.

En el momento previo a esa reinscripción, en el tránsito entre antes y después es donde se produce la subjetivación en las escrituras de Alejandra Costamagna. Anoto: la subjetivación se produce aquí no por la identificación (ni en perspectiva alegórica, ni testimonial) de sus personajes, sino gracias a una autoría que transita irónica sobre su propia escritura, que en el momento en que nos muestra una pista revela que la apariencia es un mentís, y a la que parece no bastarle la individualidad de cada relato sino que se produce como totalidad en una red narrativa compuesta por sus cuentos y sus novelas, en los que prodiga personajes y situaciones que se continúan, se intercambian, se espejean y en ese trazo se precisan, emergen cuerpo transitoriamente (personajes dúctiles que como los materiales que disponen de esa cualidad pueden deformarse sin romperse) solo para inmediatamente perder fijeza y develarse movimientos, transcursos -salvándose así del naturalismo fetichista de alguna escritura memorialística que acumula cosas como si fueran cosas, no relaciones-.

Cada relato es aquí una parte de un mapa mayor, intuimos, de una búsqueda que no termina, por trazar la afrenta. La guerra y las respuestas de cada cuerpo y cada texto emergen como huellas de ese discurrir irónico que hallamos en la niña que, otra de sí, cuenta perros arriba del árbol acosado por la jauría, mientras anticipa el desastre:

Y ve que la tía Betina sale a espantarlos con una escoba, ;fuera perros mugrientos!, con su palito de escoba que da risa. ¿Por qué no trajo el tubo de la aspiradora? Cuatrocientos noventa, cuatrocientos noventa y dos. No va a llegar a quinientos. Los perros con los hocicos llenos de pajitas de escoba ${ }^{26}$.

O que marca el pulso de la felicidad de una hija que pasa la navidad tomando sus primeras copas junto a un padre "perniciosamente hermoso"27,

25 "Rodeado por un campo de fuerza de corrientes devastadoras y explosiones, se encontraba el minúsculo y quebradizo cuerpo humano". Benjamin 2.

26 Habia una vez 23.

$27 \quad$ Idem 29. 
emborrachándose y extendiendo el tiempo de ese goce sublime mientras el retrato de la madre puntual marca como Agujas de reloj los límites de esa misma felicidad.

Ironía ésta que es la que permite a estas escrituras abrir -o doblar- ese universo cerrado, acosado de Retiro, de Campana, de Kamakura, de cualquier ciudad de un sur inexpresivo con máscara inalterable (ciudad que aparenta abjurar del acontecimiento, lo aparenta mientras produce crímenes como estrategia), que se complace en verse igual a sí misma mientras trafica espantos por lo bajo, por los túneles del acontecimiento, que solo sugiere, apunta, prolifera. Y que emerge verbigracia la narración de esa corriente subterránea.

Son los de Costamagna unos personajes que están dispuestos como observadores a veces radicalmente neutros de su historia, "animales domésticos", "naturalezas muertas" (como el Solitario frente a la maldita Inolvidable, de Violeta azulado ${ }^{28}$ ), o que, por el contrario, exponen radicalmente también la percepción del daño (como la muchacha de Cansado ya del sol, como la niña de En voz baja), pero todos capaces sí de distanciarse y retrotraer la mirada hacia sí mismos mirando el agravio que se les ha ejercido.

Iniciar el comentario de la catástrofe como catástrofe como pedía Patricio Marchant (214-22), es lo que hace Alejandra Costamagna en su temprano En voz baja, de 1996. Esa que era la catástrofe también de una voluntad frente a los perpetradores y a los vencedores, como recuerda el mismo Marchant, los del 73 pero también los que se envistieron de tales el 89, afectando con su impostura, en los vencidos, la posibilidad de rehacerse. Costamagna nombró por primera vez esta catástrofe desde un lugar de enunciación que no había existido como tal: la niñez en dictadura, que hasta su texto del 96 había sido no más que un eco, un epifenómeno de la adultez y del país, y de los padres.

Construyó ese lugar de enunciación y dijo (como en Cansado ya del sol): somos los hijos de un despojo, los hijos de un robo y de una violación, de nuestros padres, nos robaron a nuestros padres. Nunca fueron lo que pudieron ser, se los veía ahora murmurando, mascullando palabras, ninguna de rebeldía, o pocas, insuficientes. Fuimos hijos abandonados que aprendieron lo que querían ser en los sueños de unos padres que ya nunca volvieron a soñar. Fuimos pesadillas. Nos quedamos sin genealogía, solos y saqueados. Rompieron la continuidad, y la memoria que era de ellos no la tenemos, ésa es solo una parte muerta que uno deja dentro de otro; un hijo que no nació o que nació 
con sentencia de muerte; una condena o un virus mortal ${ }^{29}$. "La memoria es un almacén de desperdicios. Mi llanto copioso, mis manos callosas, yo una sombra. No hablo, los mudos afilamos la lengua con dientes de leche para que no se tulla. Éstas no son palabras", dice la muchacha en la pesadilla del padre que es también la suya, en Cansado ya del sol ${ }^{30}$.

Nos quedamos sin ellas, con nuestros padres nos robaron las palabras; fracasaron las palabras, no pudieron sustraerse al desastre.

Fracaso de la palabra: las mujeres y los hombres hablan, pero por lo bajo, no para decir sino para esconder la palabra. Se deroga la comunicación: se suspenden las visitas, se raptan las cartas, se intercepta el lazo entre padre e hijas (como en En voz baja) se cancelan los recuerdos de la madre, de la que ya no se permite hablar (como en Nadie nunca se acostumbra). El lenguaje se ha vuelto inservible: se desconfía de él: miente. El afuera es grito, el adentro, susurro. Frente al altisonante discurso del dictador y sus cómplices, los derrotados se reducen al susurro secretista, oscuro, colmado de errores pero también de traiciones, una voz reducida también por la felonía, por la apostasía de los principios.

En los textos de Costamagna la comunicación vive, se alimenta de la presencia de una segunda capa detrás de la realidad que, como un pulso de la narración, un latido del peligro, del horror, marca y condiciona su paso: el ruido de los incendios, el olor en el cielo que se quema en el horizonte, que se lo puede llevar todo en cualquier momento, los silencios o los ruidos en la pieza contigua, las histerias de la madre, una luz demasiado intensa, los olvidos de un recorrido incierto; el mal se anuncia como límite y como la segunda piel del texto, que revela su lenguaje verdadero. Así ocurre ejemplarmente en Domingos felices, donde el hombre -protagonista también de Violeta azulado ${ }^{31}$ pierde dos veces, y ve a su promesa de restitución, Muñeca, descarrilarse por el precipicio mientras los incendios son desde el inicio el signo de esa profecía autocumplida.

29 Como en la escena del cuento "Bombero en las colinas": "Él dejando una parte muerta dentro de ella, dentro de su vida miserable, y ella desvanecida a su lado, como un conejo agónico, implorando un disparo en el pecho, una bala de punta hueca, un tiro de gracia" (Últimos fuegos 55).

$30 \quad$ Cansado ya del sol 211.

$31 \quad$ Ambos de Últimos fuegos. 
¿Qué queda aquí para vivir, para comunicarse en medio de los incendios? Quedan números, datos contables para sobrevivir: se cuentan perros en la carretera, en las ciudades, a la entrada de los almacenes de pueblos en los que uno se esconde. Y se dejan de contar, se vuelven ceros, se sacrifican también cuando ya no queda más que salir.

Y cualquier restitución, cualquier intento de cuadrar las $\operatorname{cosas}^{32}$, pide un sacrificio, un cuerpo, un dolor que se personifica y se externaliza: la Dolorosa; un viudo solo que se conoce en los ojos de un perro perdido; unas mellizas que queman a su madre junto con la casa de su pérdida; un hombre abandonado y loco que también quema pero a su mujer; una mujer que abandona a un bebé dentro de un auto en una ciudad al otro lado del mundo por seguir a un hombre al que no le importa; tortugas que lloran con sus caparazones hechos peinetas; perros que más vale contarlos para que existan. Todo se quema o está amenazado con quemarse en las historias de Costamagna. El fuego opera en ellas como un límite y amenaza (ese pulso detrás de los sucesos, de los nombres), horizonte en llamas que se ejecutará como condena, pero también como revelación: Prometeo pirófono, el que porta el fuego y con él la palabra, "una sustitución, una mentira primera, un destino revelado" ${ }^{33}$. Todo se quema, sí, en su literatura, o está amenazado por el fuego, pero como en el cuento de la argentina Mariana Enríquez ${ }^{34}$, ella no se inmola, resiste, la voz, "el pájaro de la voz", cual le llama Panero (102), que es también en muchos casos el "pájaro cruel de la ruina" ${ }^{35}$, el que anuncia la ruina, cantando.

Queda también, en el interior, la mudez, el silencio como refugio y como lienzo de contraste para volver a dotar a las palabras de su cualidad ("cuando se oye bien, se calla", dice Sartre ${ }^{36}$ ), y el anhelo de una voz baja, más pequeña, que diga certezas. Pues la "voz baja" de Costamagna no es solo constricción, es sobre todo el sonido de los discursos pequeños, achicados, sobre lo cotidiano, las pequeñas épicas. Pero es también una estrategia de rehabilitación de la palabra que crece junto con la escucha: achicar, hacer

32 También se llama así un cuento de Últimos fuegos 29-32.

33 José Lezama Lima. "Las imágenes posibles".

$34 \quad$ "Las cosas que perdimos en el fuego". Cuando hablábamos con los muertos.

35 Panero 94.

$36 \quad$ 147. "En el chorro abundante de la producción actual, ¿cuándo se convierten las palabras en palabra?" Y dónde está el silencio necesario para escuchar ese cambio, pregunta por su parte Steiner (76). 
la voz de pájaro, la voz delicada que exige un oído tan atento como el que ha sido ensordecido por el estallido de la bomba, por el derrumbe de un hogar. Ese mismo que ha estado ahí, se ha presentado y quiere oír ahora una voz simple, un gorjeo, un trino. Todo lo demás, todo el ruido que se deja es superfluo porque significa la apoteosis de lo que al hombre le excede, su inmensa finitud, su piel derribada. Después de todo eso debe mentirse, relatarse (contarse en el tiempo, otra vez) y, agregaría Alejandra Costamagna, oír, oírse de otra manera a sí: imaginarse pájaro que canta, solo canta, suave, grácil, en voz baja.

\section{EL TEMBLOR DE LA ESCRITURA: ALEJANDRO ZAMBRA}

Como un recado a sus lectores, en el último cuento de Mis documentos (2014), por vez primera en su narrativa Alejandro Zambra hace pasar a primera línea al mal. En Hacer memoria, ese último cuento, el narrador, representación del escritor a quien se le ha encargado un "relato policial latinoamericano", se resiste de inicio a la tarea, se declara incómodo con el irritante mandato de hacer el reciclaje de esa especie de escritura envanecida en el estereotipo. ¿Qué hace? Nos comunica la duda del escritor y finiquita luego su indecisión narrativa con el relato de una historia suya tremenda, la más triste y desoladora historia del mal andando en su proceso mudo pero irreversible, reproduciéndose, incubándose en nuestro cotidiano, anidando en la oscuridad de nuestros lugares de refugio. Allí se cuece y comienza a hervir la maldad, allí se envenenan lenta y definitivamente los sueños latinoamericanos, también. Eso dice su última historia. Y esa verdad desoladora que cuenta pesa la profundidad de los desacomodos que su escritura venía desarrollando, como desajustes que involucran también a los discursos con que la literatura nuestra ha tratado con la fragilidad de lo humano, su vulnerabilidad y los límites de su dignidad.

Entonces, uno comprende, maravilla, que la escritura se tiñe, emerge en Zambra como una restitución: junto con esas voces precarias, vulneradas a las que da cobijo, como el resultado de la rehabilitación de su calidad de voces, es decir, de existencias independientes de la voz autorial, existencias que la superan y hablan por detrás de ella, sombreándola, definiéndola así en reversa. Esa voz autorial que se presenta cuerpo en sus textos lo logra fundamentalmente como resultado de la vocación por dar habitación a ellas, las otras del discurso narrativo que le había sido legado al escritor, en la Post. 
Si uno no se olvidara que el ser no es una esencia sino una forma de la acción -es decir, una relación con otro- ${ }^{37}$, debería confiar en que cada ser que puebla una escritura lo es en tanto se produce en último término como una forma de adaptación ${ }^{38}$, , esto es, como un satisfecho o frustrado -no importa aquí- deseo de coincidencia entre la piel y la máscara, y como su aplazamiento, el discurrir de esa discontinuidad. Como una percepción, como una corporización. Esa percepción se hallaba, en la Post, encadenada a un lenguaje narrativo que a falta de tiempo recobrado había alojado en una espesa voz autorial su hogar de retiro. Una voz vieja e impostada, un poco patética en hacer presencia, cuya sabiduría se había desgastado o había sido derruida con la ciudad. Al frente de ella, las comunicaciones insistían en la vivencia de fungibles epifanías exitistas, festejos nerviosos que cada tanto invocaban a los espectadores y cuyos rastros se acumulaban en sus livings y comedores por años, como sobras nostálgicas de una fiesta antigua y mezquina.

Ignorado por ambos discursos, el de la vieja voz y el del festejo, imposibilitado de calzar con cualquiera de sus figuras (el derrotado y el exitoso -o el talentoso, variante más sofisticada del segundo-), el ser imaginable que, como su resto, de aquello iba quedando, se internaba cada vez más en un estado liminal cuya intemperie le consumía: una organza opaca que cubría una piel más gris, triste, en eso se convertía. Así reducido, ese ser se hallaba, puede imaginar uno -y para usar una particular forma del eufemismo que se popularizó en la transición-, en situación de calle ${ }^{39}$, esto es, no en la calle, no habitándola activamente, sino que identificado, fundido con sus veredas y banquetas, con su propio abandono, en un espacio/tiempo suspendido (colgado y pospuesto): "Un árbol en precipicio", cual dibujó Bonsái (84).

37 Pensamos al ser en tanto ser negativo, como lo piensa Guy Debord: "El hombre, 'el ser negativo que es únicamente en la medida en que suprime el Ser', es idéntico al tiempo... La temporalización del hombre, tal como ella se efectúa por la mediación de una sociedad, es igual a una humanización del tiempo. El movimiento inconsciente del tiempo se manifiesta y llega a ser verdadero en la conciencia histórica". Debord 83.

\section{Rossi 100.}

39 Nombra a las personas que no tienen hogar, o, más precisamente, que alojan en portales, plazas o cualquier recodo de la ciudad, fruto, normalmente de un shock o ruptura de sus lazos social-familiares. Estas personas a menudo no son vagabundos, muchas tienen una tendencia más bien estacional respecto a estos espacios. La esquizofrenia afecta a un $1 \%$ de la población mundial, pero crece a un $30-40 \%$ entre las personas sin hogar. Fauci et al. 
Hacer la escritura de esa falta de ilación a la que sometía al ser el bandeo histérico de esa cultura y esa literatura, o las perversas relaciones entre ellas, pudo ser, pienso, una digna tarea para iniciar un plan de restitución -de ese tiempo perdido y no recobrado ${ }^{40}$-. Puede uno postular que algo así es lo que Alejandro Zambra, el autor, se propone hacer -uno postula una intención, aunque lo único que tiene es un texto, o mejor, lo hace porque posee un texto que es el límite de una intención-. Las creaciones de Zambra, de Bonsái a Formas de volver a casa, pasando por la entrañable La vida privada de los árboles, y rasgo que no abandona en Mis documentos ${ }^{41}$, parecen responder sobre todo al deseo de encontrar una escritura así como se resuelve una necesidad: "tal vez me lo invento - dice. Tal vez no me proponía nada más que descubrir, para mí, una prosa pasable. Tal vez hablé de lo que hablé porque no quería o no podía hablar de otra cosa o de otra manera. Toda literatura es, finalmente, una falla" (No leer 167). Me quedo con esto. Cuando lo que tenemos no es abundancia sino estrechez, límites, el encogimiento de una cultura, monocromía en la literatura nacional, lo que queda al escritor o a la voz que lo nombra es comenzar por hacer visible la forma de esa escasez aunque en ello se juegue, al mismo tiempo, su estabilidad.

Zambra, sus escrituras, parecen haber hecho de esa constricción su hogar, su lugar en el mundo. A través de la precaria voz en eco de un niño, de un adolescente, de narradores que preferirían no saber tanto, que ironizan sobre sus fueros, de un escritor que duda, de uno que observa "el minucioso fracaso de sus planes" (No leer 167), sus textos muestran la decisión de avanzar sobre esa escritura maltrecha no para revivirla sino, por el contrario, para darle compasivamente el tiro de gracia, extraer lo que sirve de lo que va quedando de ese lenguaje y pasar página de una vez: como dice de Coetzee y que es lo que él mismo hace, "de ese lenguaje en decadencia el escritor entresaca aquello que aún se puede decir, y procura decirlo con la mayor claridad, seca, cabalmente" (No leer 91).

Así, sin afectación, concluyente, en un compás que parece tanto más arriesgado cuanto que afecta su propia habitación en el texto, el autor se dirige vertical hacia aquélla que es la representación de esa decadencia, la pesada, la tristísima voz autorial que le ha sido legada. Y con ella es implacable: tira de

$40 \quad$ V. nota 7 en este texto.

41 Las referencias a estos libros se citarán en adelante en el texto con las siglas Bonsái, La vida, Formas y $M D$, respectivamente. 
sus cortinas, que caigan, una, dos, tres veces, que caigan todas las ilusiones. Única forma de quedarse con la semilla, eso que aún ella misma guarda como posibilidad. Había que perder la voz para salvarla -a ella y a las otras- de la mudez, o mejor, del ruido intenso que no permitía oírla, en la Post.

¿Qué es lo que ha logrado con ello el escritor? Ha provocado, así, a la percepción para que vuelva a palpar la vitalidad de aquélla como voz entre voces, las que surgen ahora finas, delineadas, cuerpo. Una voz que se deja modelar por la escritura y que solo expuesta su búsqueda pierde el miedo, surge como cuerpo que está ahí sin exigencias de presentación porque ha nacido de una necesidad ${ }^{42}$. Es entonces que la voz se revela ser, adaptación, "una historia liviana que se pone pesada" como en Bonsái (28).

El foco vuelve, entonces, quedo, de retorno a la escritura. El temblor de la instancia autorial ha sido una llamada que nos educa en la duda sobre aquélla, que nos conduce a preguntarnos por su lugar, diferir la identificación (como en ese tema de Fugazi: expandiendo el tiempo, demorando el momento de la mudanza para darle, justamente, mayor presencia ${ }^{43}$ ) y correr el foco hacia las voces que existen a su lado a quienes delicada, empáticamente, cual si la usaran por primera vez, cede la palabra. Lo que queda como remanente y producto de todo aquello es la propia escritura, que está ahora sobre la mesa $\mathrm{y}$ es una pregunta.

Una poética, la de Alejandro Zambra, que renuncia a sus patrimonios, cuya única heredad parece ser el acto mismo de desposeerse, de desistir de la ilusión del yo: en el instante en que la voz autorial decide evidenciar su labilidad, su humana fragilidad y hacer de sí un instrumento de retorno a la escritura, ahí mismo nos hacemos amigos de Julio, el protagonista, que "se avergüenza de Bonsái, su novela improvisada, su novela innecesaria, cuyo protagonista no sabe, ni siquiera, que la elección de una maceta es una forma de arte por sí misma" (Bo 87), y empatizamos con el inmenso desamparo de Julián, personaje de una novela que "sigue, aunque sólo sea para cumplir con el capricho de una regla injusta: Verónica no llega. De momento no hay imágenes de época, ni música de fondo, sólo una frase aparentemente fuera de lugar, excesiva" (La vida 66).

42 Como dice Patricio Marchant: "cuerpo hay ahí donde una terrible, imperiosa, inaguantable necesidad se impone... Cuerpo hay ahí donde hay percepción" (28).

43 Fugazi. "Sweet and Low". En el album: In on the Kill Taker. Washington, DC., 1993. 
Es en ese temblor de la escritura, en esa duda donde habita el modo de la adaptación que constituye a un ser en retorno, como un remanente de su desnudez, de su falla. Una poética de la desposesión, puede uno llamar a esta de Alejandro Zambra, que es a la vez una pedagogía sobre la restitución de una sintaxis de libertad tatuada (percibida) en el cuerpo de aquella antigua organización del sentido doblada, enjuta que fue la que recibimos en la Post y que ahora se vuelve encrucijada, posibilidad porque ya sabe-de vuelta-que la ficción "es un arte tan frágil como engañoso" (Bisama, "Una geografía" párr. 2).

Todo eso pasa en las tres novelas de Zambra y no deja de pasar en Mis documentos, once cuentos unidos por esta raíz en sus búsquedas de retorno a la escritura pero que registran ya los efectos del aire que el mismo Zambra insufló a nuestra literatura. Textos que avanzan en un diálogo que va de vuelta al mundo del afuera, en una progresión de desocultamiento de esa vida que muestra que tanto el mal como el milagro que porta la realidad siguen diferidos, lejos aún para la literatura, que viene a ser respecto a aquellos no más que una duplicación honesta de ese afuera "desangelado y represivo" (MD 86), también doloroso, como en los cuentos de la primera y segunda partes; o tan terrible como en otro extremo fascinante, como en los de la tercera: donde aún se cree en el amor verdadero o donde viajan los forzados, los que enumeran desgracias ${ }^{44}$. A todos ellos, a todas esas vidas parece querer subirlas en su pequeño barco el escritor, para el cual, como dice Claudio Magris, escribir significa algo parecido a "caminar a lo largo del río, remontar la corriente, repescar existencias naufragadas, encontrar pecios enredados en las orillas y embarcarlos en una precaria Arca de Noé de papel" (12).

Una escritura ésta que trata con los afectos de manera delicada, que cuida a sus voces, a sus personajes porque sabe que llegan a un mundo donde se los trata a gritos: "desnúdate, fornica, ejecuta tal o cual perversión"45, como ocurre en los nuevos textos de la cultura. Aquí no. Por el contrario, la voz se comunica con los personajes como si lo hiciera con seres en procesos de metamorfosis: con deferencia, prestándoles atención, intentando oír sus cambios, sus maneras de adaptarse. Y especialmente atiende a sus palabras, como si se tratara de mensajes de infancia, de decires carísimos que no se

44 "Algunos cuentan ovejas, otros enumeran sus desgracias" (MD 170), El narrador se refiere a Martín, protagonista del cuento Vida de familia.

$45 \quad$ Steiner 102. 
quiere dejar de oír porque son aquellos que nos retornan al tiempo en que habitábamos esos "terrenos vagos de infancia donde se arrastran palabras inutilizadas, traficadas, inventadas, las medias palabras de quien habla apenas, balbucidas, farfulladas", al decir de Jean-Luc Nancy ${ }^{46}$.

Alejandro Zambra otorga la posibilidad de volverse verosímiles a personajes que arriesgan y les sale pésimo ${ }^{47}$, a seres desacostumbrados a la amabilidad ( $M D$ 165), a hijos de familias donde no había muertos ni había libros ( $L a$ vida 67), al escritor de perpetuos borradores (MD 59), al que se ve perderse junto con su antiguo placer de fumar, a esa clase media que es "un problema si se quiere escribir literatura latinoamericana" (MD 191), y a Yasna, cuya historia es la de la violación de la más elemental integridad, a ellos y ellas, el autor escoge regalarles una oportunidad en la intemperie: una voz y dos paraguas, uno azul y uno negro, "el azul para el equilibrio y el negro para la lluvia" (MD 163), para seguir camino.

Y uno piensa y se convence, de que justamente con eso tratamos en sus escrituras: con el devenir de un desamparo que se convierte en camino, por la literatura. Eso inmensa, simplemente.

\section{BIBLIOGRAFÍA}

DE LOS AUTORES

Bisama, Álvaro. Los muertos. Santiago: Ediciones B., 2014. "Fotos". Volver a los diecisiete. Óscar Contardo (Ed.), 2013. 29-51. Ruido. Santiago: Alfaguara, 2012. Estrellas muertas. Santiago: Alfaguara, 2010. Música marciana. Santiago: Planeta, 2008. Caja negra. Santiago: Bruguera, 2006.

Costamagna, Alejandra. Había una vez un pájaro. Santiago: Editorial Cuneta, 2013. "Iba a caer". Volver a los diecisiete. Óscar Contardo (Ed.), 2013. 67-84. Cruce de peatones. Santiago: Ediciones UDP, 2012. Animales domésticos. Santiago: Mondadori, 2011.

$46 \quad$ Nancy 10.

47 Como dice de los suyos Julio Ramón Ribeyro. "Soy un escritor realista". Las respuestas del mudo 88 . 
Naturalezas muertas. Santiago: Editorial Cuneta, 2010.

Dile que no estoy. Santiago: Planeta, 2007.

Últimos fuegos. Santiago: Ediciones B., 2005.

Cansado ya del sol. Santiago: Planeta, 2002.

Malas noches. Santiago: Planeta, 2000.

Ciudadano en retiro. Santiago: Planeta, 1998.

En voz baja. Santiago: LOM ediciones, 1996.

Zambra, Alejandro. Mis documentos. 2014.

"Mis documentos". Volver a los diecisiete. Óscar Contardo (Ed.). 2013, 225-244. Formas de volver a casa. Barcelona: Anagrama, 2011.

No leer. Andrés Braithwaite (Ed.). Santiago: Ediciones UDP, 2010

La vida privada de los árboles. Barcelona: Anagrama, 2007.

Bonsái. Barcelona: Anagrama, 2006.

\section{DE OTROS AUTORES}

Avelar, Idelber. Alegorías de la derrota: la ficción postdictatorial y el trabajo del duelo. Santiago: Cuarto Propio, 2000.

Benjamin, Walter. El narrador. Roberto Blatt (Trad.). Madrid: Taurus, 1991 [1936].

Bisama, Álvaro. "Una geografía de la soledad”. Qué Pasa. Chile. 05.12.2013. Web. 10 diciembre, 2013. http://www.quepasa.cl/articulo/cultura/2013/12/6-13311-9-una-geografiade-la-soledad.shtml

Centro de Estudios Miguel Enríquez (CEME). Archivo Chile. Web. 31 abril, 2014. http:// www.archivochile.com/Izquierda_chilena/mapus/mapu_lautaro/ICHmlautaro0007.pdf

Contardo, Óscar (Ed.). Volver a los diecisiete. Recuerdos de una generación en dictadura. Santiago: Planeta, 2013.

Debord, Guy. La sociedad del espectáculo, s/lugar: Editorial Naufragios, 1995.

Enríquez, Mariana. "Las cosas que perdimos en el fuego". Cuando hablábamos con los muertos. Santiago: Montacerdos ediciones, 2013. 25-41.

Fauci, Anthony S. y otros. Harrison. Principios de medicina interna: compendio. España: McGraw-Hill Interamericana, 1999 (ed. 14ª).

Galindo, Regina José. Perra, Performance, Milán, Italia. 2005. Web. http://www.youtube. $\mathrm{com} /$ watch? $\mathrm{v}=\mathrm{OGGEaVcPKxs}$.

Heródoto. Historia. (VI, 11). Carlos Shrader (Trad.). Madrid: Gredos, 1995. 564-565.

Iancilevich, Ernesto. "Deterioro del lenguaje y autoritarismo en la Argentina". Revista Internacional de Pensamiento Político, vol 5, 2010. 137-150.

Kraus, Karl. "El hombre agonizante”. Escritos. José Luis Arántegui (Trad.). Madrid: Machado, 2010. 157-160. 
Lezama Lima, José. “Las imágenes posibles”. Lezama Lima. Armando Álvarez Bravo (Comp. y Prólogo). La Paz: Ed. Jorge Álvarez. 1968.

Lihn, Enrique. La orquesta de cristal. Santiago: Editorial Hueders, 2013 [1976].

Magris, Claudio. "Utopía y desencanto". Utopía y desencanto. Barcelona: Anagrama, 2001 [1996]. 7-17.

Marchant, Patricio. Escritura y temblor. Pablo Oyarzún y Willi Thayer (Eds.). Santiago: Cuarto Propio, 2000.

Martínez, Ricardo. "Los muertos, de Álvaro Bisama". Tercera cultura. Chile. 09.02.2014. Web.23 febrero, 2014. http://terceracultura.cl/2014/02/los-muertos-de-alvaro-bisama/

Nancy, Jean-Luc. Lengua apócrifa. Juan Soros (Trad.). Santiago de Chile: Cuadro de tiza ediciones, 2013.

Nietzsche, Friedrich. La genealogía de la moral. Madrid: Alianza, 2011.

Ogarrio, Gustavo. La mirada de los estropeados. México: FCE, 2010.

Ortiz Peña, Gonzalo. Niños extremistas. Santiago: Sangría editores, 2013.

Panero, Leopoldo María. Teoría del miedo. Tarragona: Igitur, 2001.

Perec, Georges. El viaje de invierno. Juan Barja (Trad.). Madrid: Abada Editores, 2006.

Pinedo C., Javier. "Chile a fines del siglo XX: entre la modernidad, la modernización y la identidad”. Universum. Año 12-1997. http://universum.utalca.cl/contenido/index-97/ pinedo.html

Reyes, Romina. Reinos. Santiago: Montacerdos ediciones, 2014.

Ribeyro, Julio Ramón. "Introducción”, La encrucijada". "La huella”. La palabra del mudo. Barcelona: Seix Barral, 2010. 9-12, 33-44.

"Soy un escritor realista". Entrevista con Irene Cabrejos de Kossuth. Las respuestas del mudo (Jorge Coaguila Selección, prólogo y notas). Lima: Lolita editores, 2012. 83-91.

Rossi, Alejandro. Manual del distraído. México: Fondo de Cultura Económica, 1996.

Rovaretti, Cecilia. "Entrevista a Alvaro Bisama". Radio Cooperativa. Chile. 25.01.2014. Web. 23 febrero, 2014. http://www.cooperativa.cl/noticias/cultura/literatura/alvaro-bisamahablo-sobre-su-nuevo-libro-a-los-muertosa/2014-01-23/122205.html

Sanhueza, Leonardo. La edad del perro. Santiago de Chile: Penguin Random House, 2014.

Santa Cruz, Guadalupe. Lo que vibra por las superficies. Santiago de Chile: Sangría, 2013.

Sartre, Jean Paul. El hombre y las cosas. Buenos Aires: Losada, 1960.

Steiner, George. Lenguaje y silencio. Barcelona: Gedisa, 2013.

Tavares, Gonçalo M. La máquina de Joseph Walser. Barcelona: Mondadori, 2007.

Vallejo, César. "Los heraldos negros". Los heraldos negros. Trilce. Barcelona: Ediciones Saturno, 1972. 13.

Vial, Juan Manuel. "El todo a pedazos". La Tercera. Santiago, Chile. 21.12.2013. Web. 21 julio, 2014. http://www.alejandrozambra.com/el-todo-a-pedazos/

Viera Gallo, María José: “Alejandro Zambra: "Lo mío es el ocio, no el negocio". Revista Capital. Santiago, Chile. 19.04.2013. Web. 28 de junio, 2013. http://www.capital.cl/ cultura/alejandro-zambra-lo-mio-es-el-ocio-no-el-negocio/ 
Wilde, Óscar. Intenciones. La decadencia de la mentira. Madrid: Valdemar, 2012.

Zúñiga, Diego. "Entrevista a Alvaro Bisama". Revista Contrafuerte. Santiago d+e Chile, $\mathrm{N}^{\circ}$ 2, diciembre de 2009. Web. 29 mayo, 2014. http://revistacontrafuerte.files.wordpress. com/2009/08/contrafuerte1.pdf

Camanchaca. Santiago de Chile: Random House Mondadori, 2012. 